\title{
Application of Multitask Driven by Program Guidance in Teaching of 'Digital Signal Processing'
}

\author{
Feng Zhang \\ School of Electronic Information Engineering, \\ Xian Technological University \\ Shanxi China \\ zf_zx963@163.com
}

Xianfeng Shi

School of Electronic Information Engineering, Xian Technological University

Shanxi China

11288620@qq.com

\section{Li Zhao}

School of Electronic Information Engineering, Xian Technological University

Shanxi China

Pilly_lily@126.com

\author{
Zhishuai Bai \\ School of Electronic Information Engineering, \\ Xian Technological University \\ Shanxi China \\ 431763850@qq.com
}

\author{
Yinxi Xu \\ School of Electronic Information Engineering, \\ Xian Technological University \\ Shanxi China \\ 1075818920@qq.com
}

\author{
Yuqin Dou \\ School of Electronic Information Engineering, \\ Xian Technological University \\ Shanxi China \\ 925879353@qq.com
}

\begin{abstract}
Program guidance and task driven are the teaching methods that are based on cognitive learning theory, constructive learning theory and action learning theory, which have a positive effect on the cultivation of innovative consciousness, engineering application consciousness and the habit of autonomous learning. To solve the problem of the boring teaching process, the learning difficulty process and the lack of the students' application ability in the course of 'digital signal processing' which is the electronic information related professional courses, this paper integrates these two methods, combining the engineering program 'the analysis of the vibration signal for rotated machine' with the reasonable task design to apply to the course teaching. On these processes, it is based on the research project to guide to cultivate the ability to solve engineering problems by using the theory, principle and method of digital signal processing, and it is based on multiple tasks of reasonable division and design to drive to cultivate innovative consciousness and exercise the ability to solve the problems so that it can promote to forming the research learning quality. Through practice, curriculum teaching mode which is based on program guidance and multitask driven achieved good results, improved the teaching quality of the course 'digital signal processing', which played a positive role in cultivating practical personnel and the research talents in the relevant professional.
\end{abstract}

Keywords-Program guidance; Task driven; Digital signal processing; Inquiry learning; Innovative consciousness

\section{INTRODUCTION}

Program guidance and task driven are the teaching methods that based on cognitive learning theory, constructive learning theory and action theory, which have a positive effect on the cultivation of innovative consciousness, engineering application consciousness and the habit of autonomous learning. The paper combines these two teaching methods organically ,and applies to the teaching course 'digital signal processing, which is related major of electronic information for undergraduate, and though the guidance of actual scientific research to cultivate students' ability in solving practical problems by using the principle and theory of digital signal processing ,and though multitask driven to cultivate the quality of innovation consciousness and research learning, which obtained a good teaching method [1].

\section{MULTITASK DRIVEN TEACHING METHOD UNDER THE GUIDANCE OF PROGRAM GUIDANCE}

\section{A. Program guidance teaching}

Program guidance teaching method which is established based on the cognitive learning theory, is a kind of transformation from the traditional teaching method 'theory first, then practice'. This kind of teaching method takes solving practical method as teaching purpose, as the motivation of solving the problems to achieve the knowledge acquisition and ability cultivation during the teaching process. In the professional basic courses and specialized courses in Engineering Specialty, guiding by program to organize and carry on curriculum teaching, combing the curriculum theory with practical engineering program and practical application organically ,which can cultivate students' the awareness of engineering, strengthen the understanding of theoretical knowledge and simulate the interest in learning[2].

\section{B. Task driven teaching method}

Task driven teaching method is a kind of interactive teaching method which is established on the basis of constructionist teaching theory, hiding teaching content in a series of carefully designed tasks, to let the students find the problems and find the solution to the problem through the 
analysis and implementation of the task, so as to cultivate students' sense of innovation, innovative ability, engineering application consciousness and the habit of autonomous learning. Task driven teaching method has a good promotion for the transition from the teacher-centered traditional teaching pattern to the student-centered research teaching pattern for classroom teaching[5].

\section{The combination of program guidance and multitask driven}

Multitask driven teaching under the program guidance is effectively integration of program guided teaching and task driven teaching, taking engineering program as carrier, decomposing project objectives into a series of relatively independent tasks, the implementation of specific tasks as the basic means to achieve the objectives of the project, which can better play the role of the two in the practical teaching. The introduction of multitask, on one hand, the overall objectives of the project breaks up the whole into parts, which have better implication; on the other hand, appropriately extended and carefully designed multiple tasks, the coverage of curriculum theory knowledge is more comprehensive, which avoid the lack of a single task. Meanwhile, Multiple tasks are easier to implement in groups during the teaching process, cultivating the ability of solving the problems in teamwork[7].

\section{PROGRAM GUIDANCE AND MULTITASK DRIVEN IN TEACHING 'DigITAL SigNAL PROCESSING'}

\section{A. Curriculum Characteristics Analysis}

Digital Signal Processing' is an important professional basic course of electronic information related major. This course is abundant in content, and closely combined with specialized courses, but the principle is abstract and the formula is complicated. Much mathematical knowledge involved in depth. At the same time, the application of course content and related technology in the field of signal processing are more and more widely, so the course also has a very strong practical. Classroom teaching based on the traditional teaching methods, even using the multimedia teaching during the class, introducing the simulation software, combined with a large of engineering practice case, there are still some problems that the teaching process is relatively boring, The learning process is very difficult, the students' communicative ability is ubiquitously lacking, which is not suitable for the aim of cultivating the applied talents and research talent. From the characteristic of strong practice and application in 'Digital signal processing', Multitask driven teaching method under the program guidance is introduced into course teaching. Through the actual engineering projects and the reasonable design of the task, students' learning interest can be motivated, promoting the relationship between theoretical content and engineering application, cultivating students" ability to solve practical engineering problems by using the principle of digital signal processing, improving the teaching quality, realizing the transition to the research teaching mode[6].

\section{B. Program guidance promoting the combination between curriculum principle and application}

According to the professional characteristics of electronic information related major, in the course of teaching, taking the actual engineering project as the guide, it can promote the combination between curriculum theory and practical application. For the wide application of signal processing technology in the field of industrial fault diagnosis, choosing the actual research project "Online monitoring and fault diagnosis system for steam turbine vibration" as the implement course project to guide the teaching for the foundation. The whole overall structure and design of online monitoring and fault diagnosis system for steam turbine vibration is shown as Fig. 1.

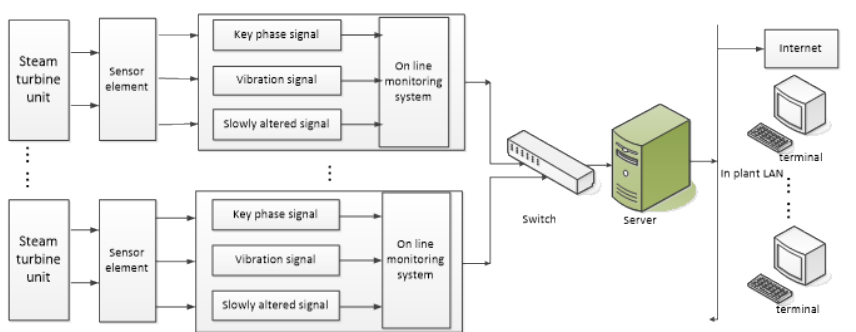

Fig. 1. Online monitoring and fault diagnosis system for steam turbine vibration

The whole system in structure belongs to the design of distributed system, mainly consists of a number of online monitoring system, server, communication interface and communication lines, synchronous operation of host and slave computer. The slave computer, composed of on-line monitoring device, located near the steam turbine unit, is the device of data acquisition and analysis, which can complete the data acquisition, processing and analysis tasks independently, then transform the data in form of the digital signal to the server computer through the network server. The host computer belongs to the fault diagnosis system, and the industrial computer is as the server, which is responsible for data communication, data storage, historical data analysis, trend analysis, fault diagnosis and web publishing, also can send the control parameters of the system to each online monitoring system, in order to adjust the working state and working parameters of the online monitoring system. Host server is also responsible for publishing the analysis of the results to the factory LAN or wide area network, all data communications are carried out through the network. Combined with the nature of the course and the actual content of the undergraduate digital signal processing teaching, selecting one of the core content of the whole system that vibration signal analysis and processing function is as curriculum implementation of the project to guide teaching implementation of specific projects. This project covers the contents of the signal acquisition, signal filtering and signal frequency domain analysis, and these contents are the core of the curriculum teaching in "digital signal processing" related to electronic information for undergraduate, which can better realize the combination between curriculum theory and practical application.

\section{Multitask driven implementation the transition of research teaching mode}

The project "rotating machinery vibration signal analysis and processing "as a guide, through analysis of the overall function and technical requirements, combined with the content 
course arrangement and the knowledge module, the entire project implementation is divided into three specific tasks, which is shown in Fig. 2 :

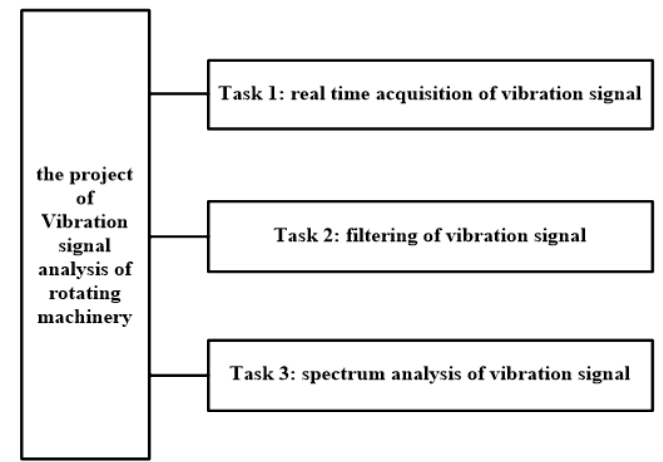

Fig. 2. Task division and design under the guidance of program guidance

These three tasks are relatively independent and basic principles correspond to the knowledge modules of these three core curriculum: the signal sampling (task 1), filter design (Task 2) and signal frequency domain analysis (task 3), which facilitate the phased implementation according to the course schedule; meanwhile, there are some links and interfaces between these tasks, which compose the core content of the whole project, to ensure the integrity of the project objectives. Reasonable project decomposition and task design can effectively stimulate students' interest in learning; cultivate the consciousness of engineering application and innovation ability During the specific teaching process, through the project understanding, analysis tasks and task implementation students can find the problem, to solve practical problems by using the course theoretical knowledge, which realize the transition from curriculum teaching model to research teaching model, in some degree to solve the problems of teaching difficulty, learning difficulty, the lack of the knowledge using, insufficiency in engineering application[7].

\section{Implementation and effect evaluation}

By the analysis of the above and the relationship between the project and the task we can see, the implementation of multitask driven by program guidance is based on task driven teaching. According to the relevant theory of the task driven teaching method and the practical characteristics of the course, the implementation of the task driven teaching method is shown in Fig. 3.

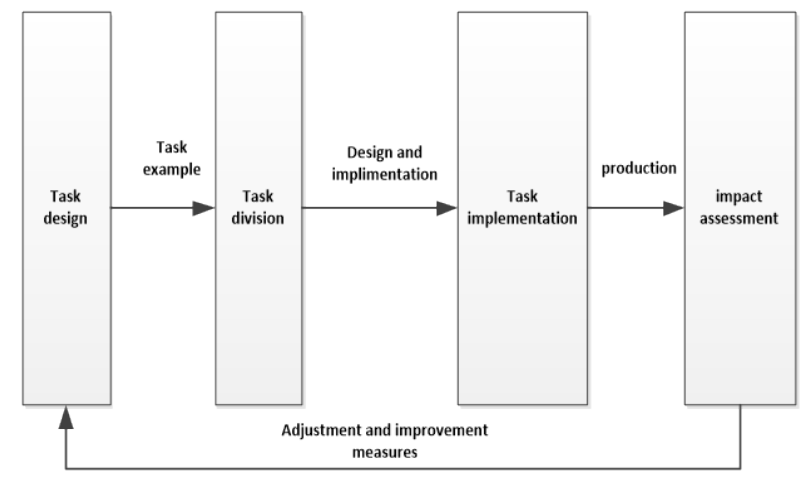

Fig. 3. The implementation of task driven Teaching
This implication plan takes students as the center, emphasis on the ability cultivation of finding and solving problems; the teacher is mainly responsible to design for the task, and to guide students during the implementation process. In the implementation plan, the good mission design is basis of task driven teaching, which designed by teachers according to the project. Task decomposition is carried out according to the course content and knowledge module. Task implementation takes the student as the center to carry on, and the teacher provide the necessary instruction. Effect evaluation carries out, combined with task completion process, production and actual project technical indicators, evaluation results on the one hand, as an indicator of curriculum assessment, on the other hand, as a basis for the task adjustment and perfection. Specific course teaching practice proves that multitask driven teaching under the guidance of the project can mobilize the enthusiasm of students learning, learning interest and class participation, completing the design plan and Specific task implementation under the driven by the project's lead and mission requirements, submitting the production so To achieve the purpose of training research ability .meanwhile, The introduction of feedback mechanism in the implementation process ensures the teaching effect, Quality of task design and the effective implementation of this teaching method[2-3].

\section{SUMMARY}

In this paper, two teaching methods, the program guidance and task driven method were integrated, combining the actual engineering project and reasonable task design, applying to the teaching "digital signal processing" course. The guidance of practical scientific research projects cultivates the students to solve practical problems by using related theories, principles and methods of digital signal processing. Multitask driving is effective in cultivating students" sense of innovation, exercising the ability to solve problems, promoting the formation of the research learning quality. The course teaching method, which is based on multitask driven by program guidance has obtained the good teaching effect through practice, improving the teaching quality of "digital signal processing" course, which has played a certain positive role in realization of the cultivating practical talents and research talents[4-5].

\section{REFERENCES}

[1] Duanyuan BAI, Zhen HU, Mingqiu LI. Discussion on theTask Driven Method in the Teaching of Automation Technology and Application[J]. Studies in Literature and Language,2015,113:

[2] Susan K. Jacobson, Rafael Robles. Ecotourism, sustainable development, and conservation education: Development of a tour guide training program in Tortuguero, Costa Rica[J]. Environmental Management, 1992, 166

[3] Ali Nagia S,Hodson-Carlton Kay,Ryan Marilyn. Web-based professional education for advanced practice nursing: a consumer guide for program selection.[J]. The Journal of Continuing Education in Nursing, 2005,331

[4] Kamel Hussein Rahouma, Peter Zinterhof. Developing a Hypertext GUIDE Program for Teaching the Simple Tasks of Maintaining and Troubleshooting the Educational Equipments[J]. Journal of Cases on Information Technology (JCIT), 2002,41

[5] Pelletier David, Corsi Allison, Hoey Lesli, Faillace Silvana, Houston Robin. The program assessment guide: an approach for structuring 
contextual knowledge and experience to improve the design, delivery, and effectiveness of nutrition interventions.[J]. The Journal of Nutrition, 2011,14111.

[6] Saunders Ruth P,Evans Martin H,Joshi Praphul. Developing a processevaluation plan for assessing health promotion program implementation: a how-to guide.[J]. Health Promotion Practice, 2005, 62:
[7] Bram J. Keulers, Miel J. Keulers, Marc R. M. Scheltinga, Paul H. M. Spauwen. Evidence-based development of interactive patient education programs: a guide for achieving optimal computer-based patient education[J]. European Journal of Plastic Surgery,2006,294: 